\title{
Microstructural characteristics of fibre laser welded joint of dual phase steel with complex phase steel
}

\author{
P. Švec ${ }^{1 *}$, A. Schrek ${ }^{1}$, M. Dománková ${ }^{2}$ \\ ${ }^{1}$ Institute of Technologies and Materials, Faculty of Mechanical Engineering, \\ Slovak University of Technology in Bratislava, Pionierska 15, 83102 Bratislava, Slovak Republic \\ ${ }^{2}$ Institute of Materials Science, Faculty of Materials Science and Technology in Trnava, \\ Slovak University of Technology in Bratislava, Bottova 25, 91724 Trnava, Slovak Republic
}

Received 2 January 2018, received in revised form 24 January 2018, accepted 26 January 2018

\begin{abstract}
Microstructures in the sub-zones of butt joint consisting of dual phase DP980 steel and complex phase CP780 steel with a thickness of $1.5 \mathrm{~mm}$ welded using fibre laser process were evaluated. The microstructure in the fusion zone was built of an approximately equal portion of martensite and lower bainite. In both coarse-grained heat affected zones near DP980 and CP780 steel dominant presence of lath martensite and a minor portion of lower bainite were observed. Similar microstructures were created in both fine-grained heat affected zone near DP980 and near CP780 steel but with the presence of ferrite and tempered martensite in region heated to lower peak temperatures. Mainly $\mathrm{M}_{3} \mathrm{C}$ carbides precipitated in lower bainite, and mostly MX carbonitrides precipitated in martensite. Created microstructures corresponded with microhardness profile across the joint. The highest microhardness of $476 \mathrm{HV}_{0.1}$ was measured in the coarse-grained region of the heat affected zone near DP980 steel with a high portion of martensite.
\end{abstract}

Key words: dual phase steel, complex phase steel, fibre laser welding, microstructure, microhardness

\section{Introduction}

Advanced high strength steels (AHSSs) with zinc coatings such as high strength low alloy (HSLA) steels, dual phase (DP) steels, complex phase (CP) steels, TRIP steels, TWIP steels, martensitic steels, press hardened steels, etc. have been intensively studied [1-6]. A combination of high strength level and toughness of these steels is the consequence of their microstructure together with precipitation hardening and grain boundary strengthening mechanisms achieved through thermo-mechanical processing. AHSSs are used in a wide variety of applications as structural components, pressure vessels and line pipes, and in shipbuilding, offshore construction, automotive, industrial vehicles, lifting and cranes. The application of AHSSs for such components enables lighter and more slender products and reduces construction costs without loss of structural integrity [5-7].
The superior mechanical properties of AHSSs in comparison with standard steels enable the use of thin-walled sections of these steels in modern car bodies, significantly reducing the weight of a vehicle without compromising other attributes such as safety, performance, recyclability and cost. Frames, crossbeams, vertical beams, side impact beams, and safety elements are often made of tailor welded blanks (TWBs) consisted of AHSSs $[1,8]$. The TWBs are semi-finished parts that consist of at least two single sheets that are welded together prior to the forming process. The sheets can exhibit different mechanical properties, thickness or coatings. Using TWBs enables an adaptation to locally different loading conditions or other requirements in part [7, 9-10]. Other advantages of joining prior to the forming are the reduction of the number of the required forming tools, the higher accuracy in the forming process and the enhanced use of material which leads to lower production costs. The most important advantage of parts

*Corresponding author: tel.: +421 905326211; e-mail address: pavol.svec@stuba.sk 
made from TWBs is the weight reduction compared to conventional products. A car body manufactured using TWBs and AHSSs can achieve a $25 \%$ weight reduction $[7-10]$.

The TWBs welded of DP and CP steels have increased applications potential due to their excellent properties. The excellent mechanical properties of DP and CP steels are the consequence of their multiphase structure. Most often the microstructure of DP and CP steel is developed by accelerated cooling of sheets after controlled rolling in the temperature range between $A_{\mathrm{c} 1}$ and $A_{\mathrm{c} 3}$. The process is a flexible one and allows different combinations of created phases and their relative volume ratio. The microstructure of DP steel can consist of up to $70 \%$ martensite in the fine-grained ferrite matrix and up to $10 \%$ of retained austenite. The tensile strength up to $1200 \mathrm{MPa}$ and unit elongation up to $20 \%$ can be achieved at a proper volume ratio of ferrite and martensite phases [11-14]. The complex microstructure of CP steels consists of a ferritic matrix with martensite and bainite, and it is the consequence of high strength, improved impact toughness with sufficient formability of CP steel sheets $[15,16]$.

When joining DP steels with CP steels in TWB parts, the good ration of strength deformation properties can be achieved. These properties guarantee the strength at still sufficient formability of safety car body parts made of TWBs using deep drawing process. The joining of sheets in TWBs is usually done by fibre laser welding because of excellent beam quality and high brightness of fibre lasers, high power, deep penetration, low beam divergence, high plug efficiency, and compact size coupled with flexible beam delivery $[6,8,17-21]$. Low heat input is an important characteristic of laser welding, and it is the consequence of small fusion zone (FZ) and heat affected zone (HAZ) and the lower cost and higher flexibility compared to other welding methods. Low heat input welding methods can produce the fine-grained microstructures that provide the strength and toughness of the joint, and they also have the benefit of decreasing welding thermal distortion [11, 22-24].

Microstructure changes accompanying the laser welding affect the final properties, mainly increase the strength and decrease formability in weld region of TWB. Although strength increasing can be positive for final properties of car body parts, formability decrease can be limiting for both production of parts and their applications. The proper microstructure assures proper ratio between strength and formability $[3,25,26]$. The microstructure is affected mainly by the chemical composition of base materials (BMs), sheets thicknesses and welding parameters, such as beam power, welding speed and others. The final microstructure in FZ and HAZ weld is a consequence of rapid heating and cooling cycles with melting and solidification happening in a significantly brief time.
FZ and HAZ are characterised by increased hardness and decreased plastic properties [27-29]. The welding process influences the weld imperfections, which are related to the weld geometry such as concavity, sagging, impurities or gaseous elements, porosity, pinholes or craters [30-32]. Several works were devoted to the laser welding of different DP steels, such as DP600, DP780, DP800, DP980, DP1000, and DP1180 grades with a different portion of ferrite and martensite phases $[1,3,10,11,18,22,23,25-28,30,33-$ 36]. Other works were focused on laser welding of DP steels with HSLA $[2,31,32]$ and TRIP steels [2, 9, 13, 37-42], but fewer works were focused on welding of DP steels with CP steels. The microstructure in the sub-zones of welded joints has been studied to define properties of welded joints. In some works, authors demanded fully martensitic microstructure in FZ and HAZs of laser joints consisting of DP980 steel [18, 25, 26]. Other authors identified microstructure consisting of martensite and lower bainite [43]. Many authors measured the microhardness in the sub-zones of welded joints because the microhardness measurement is helpful for microstructure identification. Majority of authors observed hardness increase in the FZ and both HAZ near DP and CP steels after laser welding process in consequence of microstructure changes in these sub-zones of joints, but there are differences in location of maximum hardness in the weld. Some authors measured the maximum hardness in the FZ, others in the coarse-grained supercritical HAZ. Higher hardness causes reduction of formability accompanied by significant lack of toughness [3, 25, 31, 32]. However, the reduction of hardness in the tempered region of HAZs has been described at laser welding of DP and CP steels. This phenomenon is generally known as HAZ softening, and it has detrimental effects on the weld properties with strain localisation in the HAZ at lower stress than can be supported by BM [27, 33, 36]. Previous studies on DP steel joints have indicated that the subcritical zone was softened to a lower hardness than that of BM due to martensite tempering at the HAZ [1]. HAZ softening is less visible at using fibre laser welding compared to arc welding [1]. Whereas more information about microstructure evolution of fibre laser welded joints is needed, this work attempts to characterise the microstructure and microhardness in the sub-zones of DP980 with CP780 steel fibre laser welded joint.

\section{Experimental procedures}

Dual-phase DP980 steel and complex phase CP780 steel sheet with a thickness of $1.5 \mathrm{~mm}$ and zinc coating of $100 \mathrm{~g} \mathrm{~m}^{-2}$ were used for fibre laser welding. The chemical composition of the experimental steels is given in Table 1, and their mechanical properties 
Table 1. Maximal concentration of alloying elements in (wt.\%) for DP980 and CP780 steel

\begin{tabular}{lcccccccccc}
\hline Steel & $\mathrm{C}$ & $\mathrm{Mn}$ & $\mathrm{Si}$ & $\mathrm{Al}$ & $\mathrm{P}$ & $\mathrm{S}$ & $\mathrm{V}$ & $\mathrm{B}$ & $\mathrm{Cr}+\mathrm{Mo}$ & $\mathrm{Nb}+\mathrm{Ti}$ \\
\hline DP980 & 0.23 & 2.5 & 0.8 & 2.0 & 0.08 & 0.015 & 0.2 & 0.005 & 1.0 & 0.15 \\
CP780 & 0.18 & 2.2 & 0.8 & 2.0 & 0.08 & 0.015 & 0.2 & 0.005 & 1.0 & 0.15 \\
\hline
\end{tabular}

Table 2. Mechanical properties of DP980 and CP780 steel

\begin{tabular}{lccc}
\hline Steel & Tensile strength $(\mathrm{MPa})$ & Proof strength $(\mathrm{MPa})$ & Elongation $(\%)$ \\
\hline DP980 & min. 980 & $600-750$ & min. 10 \\
CP780 & min. 780 & $500-700$ & min. 10 \\
\hline
\end{tabular}

are compared in Table 2. The chemical concentration of used steels (Table 1) slightly differs in contents of carbon and manganese with a higher amount of these elements in DP980 grade dual phase steel. This is the consequence of the higher strength of DP980 steel compared to CP780 complex phase grade steel (Table 2), but elongations of both steels are the same.

The experimental steel sheets were butt welded using the solid-state fibre laser IPG YLS-5000 with a maximum output of $5000 \mathrm{~W}$, the wavelength of 1060 $\mathrm{nm}$ and a fibre diameter of $100 \mu \mathrm{m}$ and with the welding head Precitec YW52 at the distance of $250 \mathrm{~mm}$ from the welded sheets. Welding experiments were conducted on sheets with the length of $200 \mathrm{~mm}$ and width of $100 \mathrm{~mm}$ along the longitudinal edges, which were milled before welding. The butt joints were fibre laser welded without filler metal and without shielding atmosphere at the beam power in the interval from 800 to $5200 \mathrm{~W}$, the welding speed from $10 \mathrm{~mm} \mathrm{~s}^{-1}$ to $120 \mathrm{~mm} \mathrm{~s}^{-1}$, and the focal position from 5 to $12 \mathrm{~mm}$. However, only joint prepared at the beam power of $3900 \mathrm{~W}$, welding speed of $70 \mathrm{~mm} \mathrm{~s}^{-1}$ and focal position of $10 \mathrm{~mm}$ is in details characterised in this study. These parameters enable to prepare joints with the required geometry and strength at the highest experimental welding speed. The microstructures were studied on the cross-sections of welded joint, which were prepared using standard metallographic techniques. The microstructures were observed using Axiovert 40MAT light microscope. Image analysis was used to measure grain sizes in weld sub-zones. JEOL JSM-IT300 scanning electron microscope (SEM) with energy-dispersive spectroscopy (EDS) were employed for microstructure identification and chemical analysis of created phases. Both carbon replica samples and thin film samples were prepared for transmission electron microscopy (TEM) analysis. Carbon replica and thin film samples were observed using two transmission electron microscopes JEOL 200 CX with an accelerating voltage of $200 \mathrm{kV}$, and Philips CM 300 with an accelerating voltage of $300 \mathrm{kV}$. Selected area electron diffraction (SAED) was used for qualitative phase analysis of weld sub-zones. Microhardness profiles were measured through a middle section of weld sub-zones parallel to the surfaces of sheets using Vickers indenter with a load of $100 \mathrm{~g}$ and distance between indentation of $0.1 \mathrm{~mm}$. The samples for tensile tests were prepared from welded joints, and the tests were carried out using the testing machine Instron 195 at room temperature and a crosshead speed of $10 \mathrm{~mm} \mathrm{~min}^{-1}$.

\section{Results and discussion}

Dominant microconstituents created in BMs, FZ and HAZs of the welded joint are documented using SEM and TEM. The microstructures of both HAZs are documented in the coarse-grained and fine-grained regions of HAZs. The coarse-grained region is identical with high temperature heated part of the supercritical zone in the vicinity of fusion boundary. The fine-grained region lies within both the intercritical zone and low temperature heated part of supercritical zones near the $A_{3}$ critical temperature.

\subsection{Cross-section of fibre laser welded joint}

The cross-section of fibre laser welded joint with its sub-zones can be seen in Fig. 1. The sub-zones are characterised by hourglass shape typical for penetration keyhole welding with a smaller thickness of FZ in the middle of the weld and wider thickness of FZ at both top and bottom of the weld. The interfaces between both BMs and HAZs are quite narrow. The joint is characterised by the slight concavity of the face and root sagging but without porosity or cracks. The FZ consists of coarse columnar dendritic grains that are oriented perpendicular to the fusion boundary. Because of the maximum rate of heat removing, the grains tend to grow in that direction with the coarse-grained region created in the vicinity of the fusion boundary with the highest peak temperature above the $A_{\mathrm{c} 3}$ critical transformation tempera- 


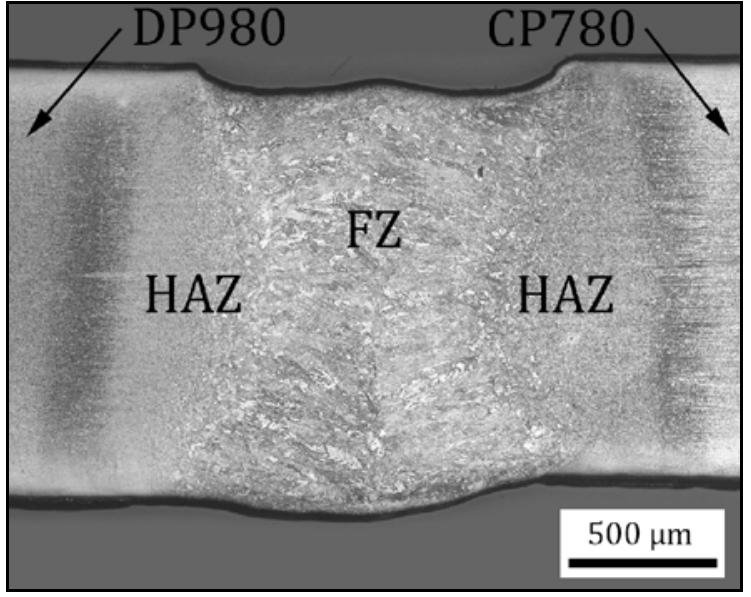

Fig. 1. Cross-section of welded joint of DP980 steel with CP780 steel (FZ - fusion zone, HAZ - heat affected zone).
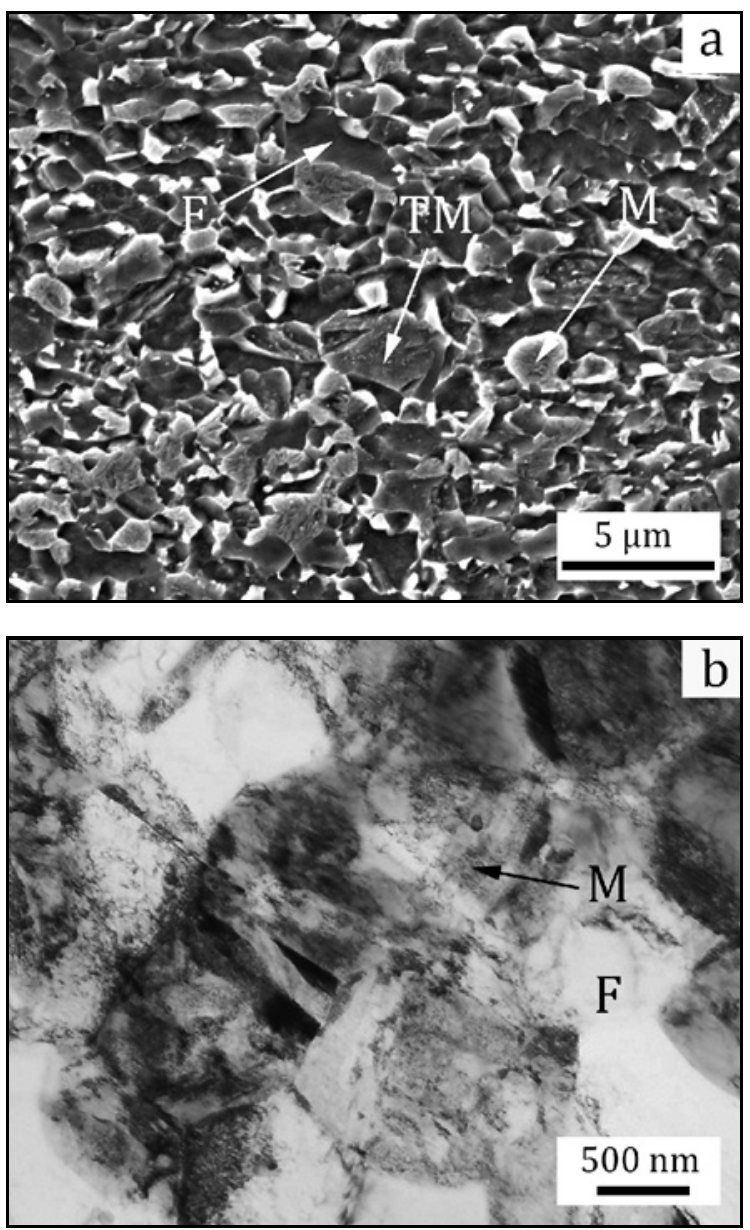

Fig. 2. Microstructure of DP980 steel: (a) SEM image, (b) TEM image ( $\mathrm{F}$ - ferrite, $\mathrm{M}$ - martensite, $\mathrm{TM}$ - tempered martensite).

ture. The grain size in both HAZs decreases with the distance from the fusion boundaries.
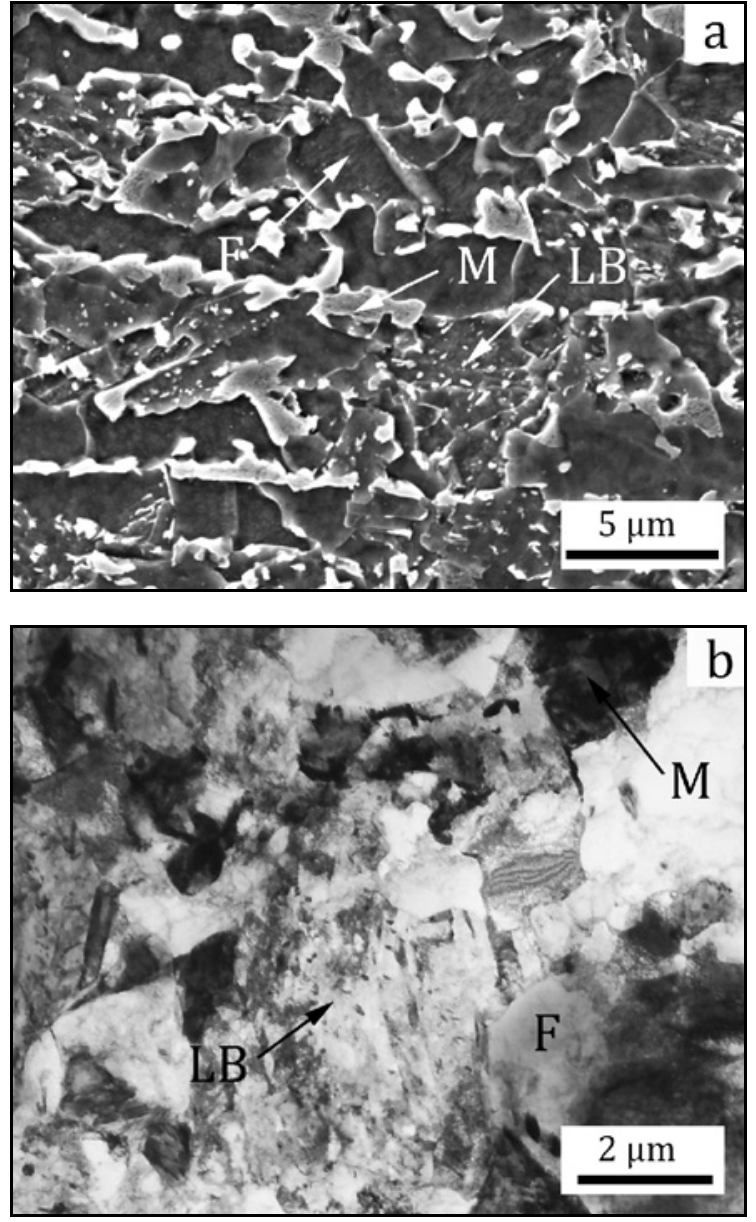

Fig. 3. Microstructure of CP780 steel: (a) SEM image, (b) TEM image ( $\mathrm{F}$ - ferrite, $\mathrm{M}$ - martensite, LB - lower bainite).

\subsection{Microstructures of base materials}

Both SEM and TEM micrographs revealing the microstructure of DP980 steel BM are documented in Fig. 2. The microstructure is fine-grained with average grain size under $1 \mu \mathrm{m}$ and consists of martensitic islands in ferrite matrix with an equal portion of ferrite and martensite. A small portion of tempered martensite with very fine $\mathrm{M}_{3} \mathrm{C}$ carbide precipitates identified by EDS method is also visible in SEM image (Fig. 2a). The presence of tempered martensite can be explained by high martensite start temperature of DP9800 steel. This temperature is according to works $[44,45]$ from 414 to $434{ }^{\circ} \mathrm{C}$ and so the martensite can self-temper during thermo-mechanical processing. White areas of ferrite and dark areas of lath martensite with a high density of dislocations can be distinguished in thin film sample in Fig. 2b. The fine-grained microstructure promotes good formability of DP980 steel with the minimal elongation of $10 \%$ given in Table 2.

Both the SEM and TEM micrographs of CP780 steel BM microstructure are depicted in Fig. 3. The 

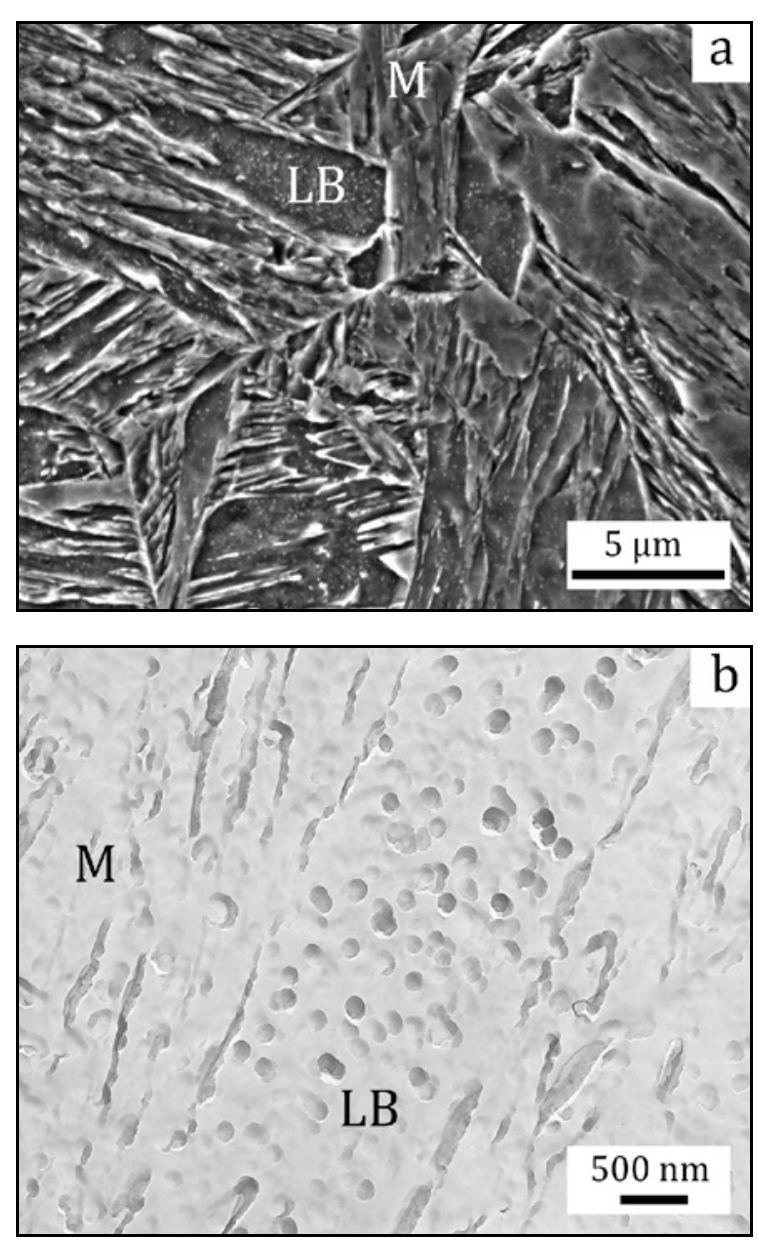

Fig. 4. Microstructures in FZ of the weld: (a) SEM image and (b) TEM image (M - martensite, LB - lower bainite).

microstructure of CP780 steel BM consists of ferrite matrix with rows of martensite and lower bainite. Ferrite grains are characterised by slight crystallographic texture and heterogeneity in grain size in the interval from 2 to $15 \mu \mathrm{m}$ (Fig. 3a). Secondary $\mathrm{M}_{3} \mathrm{C}$ carbides, which identification was confirmed by SAED analysis, precipitated in lower bainite (Fig. 3a,b). These carbides are larger compared to precipitates in Fig. 2a. Martensite has lath morphology and high density of dislocations as can be seen in thin film sample in Fig. 3b. Lower bainite has acicular morphology with a high density of dislocations.

\subsection{Microstructures in the fusion zone of the weld}

The microstructures within the FZ are the results of solidification of columnar large prior-austenite grains, and solid phase transformation of these grains under the fast cooling conditions. The cooling rate of FZ is extremely fast, i.e. much higher than the critical cooling rate of martensite forming [1]. Cooling rate calculated through modelling in [11] is of the order of $10^{5} \mathrm{C} \mathrm{s}^{-1}$ and the critical cooling rate for DP980 steel to achieve martensitic transformation is about $400{ }^{\circ} \mathrm{Cs}^{-1}$ [11]. Regardless of the fast cooling rate of FZ, lath type martensite and lower bainite with an approximately equal portion of these microconstituents formed in FZ, as shown in Fig. 4 depicting the substructure of FZ. The same morphological characteristics of lath martensite and lower bainite can be seen in SEM micrograph in Fig. 4a and TEM micrograph in Fig. $4 \mathrm{~b}$ is represented by carbon replica. Fine particles precipitating inside the laths of lower bainite can be seen in both Fig. 4a and Fig. 4b. The identification of martensite and lower bainite was confirmed by TEM images that are presented in Fig. 5 and Fig. 6 .

The thin film sample depicting the detail of low carbon martensite with interlath retained austenite can be seen in bright field TEM image in Fig. 5a. Interlath retained austenite between the martensitic laths was identified by dark field TEM image with reflections corresponding to the retained austenite (white areas) in Fig. 5b and in the SAED pattern of austenite in Fig. 5c.

The detail of lower bainite is documented in thin film sample in Fig. 6. Lower bainite laths with fine $\mathrm{M}_{3} \mathrm{C}$ carbides precipitating inside these laths are depicted in bright field TEM image in Fig. 6a. The dark field TEM image in Fig. $6 \mathrm{~b}$ reflects bright $\mathrm{M}_{3} \mathrm{C}$ carbide precipitates in this image. $\mathrm{M}_{3} \mathrm{C}$ carbide phases were identified in SAED pattern in Fig. 6c and their presence and morphology confirm the identification of lower bainite.

The microstructure in FZ can be compared with several authors. Fully martensitic or predominantly martensitic microstructure in FZ was confirmed in works $[1,18,25,26,28]$ which were focused on fibre laser welding of various DP steels with a thickness of $1.2 \mathrm{~mm}$. The FZ contained lath martensite at laser welding of CP800 steel grade with a thickness of $2.5 \mathrm{~mm}$ in work [43]. Mainly martensitic microstructures were observed in works [31, 32], and the FZ contained martensite and bainite in work [46] which evaluated laser welding of DP980 with HSLA steel with a thickness of $1.2 \mathrm{~mm}$.

\subsection{Microstructures in $H A Z$ near DP980 steel}

The microstructures created in HAZ of a weld depend on the local thermal cycles characterised by the peak temperatures and cooling rates and their relation to the theoretical critical transformation temperatures $A_{1}$ and $A_{3}$ in the time-temperature transformation diagrams of welded steel. For DP980 steel, the $A_{\mathrm{c} 1}$ critical temperature, which corresponds to the temperature at which the DP980 steel BM begins to transform to austenite, is about $724^{\circ} \mathrm{C}$. The $A_{\mathrm{c} 3}$ critical temperature, which corresponds to full transfor- 

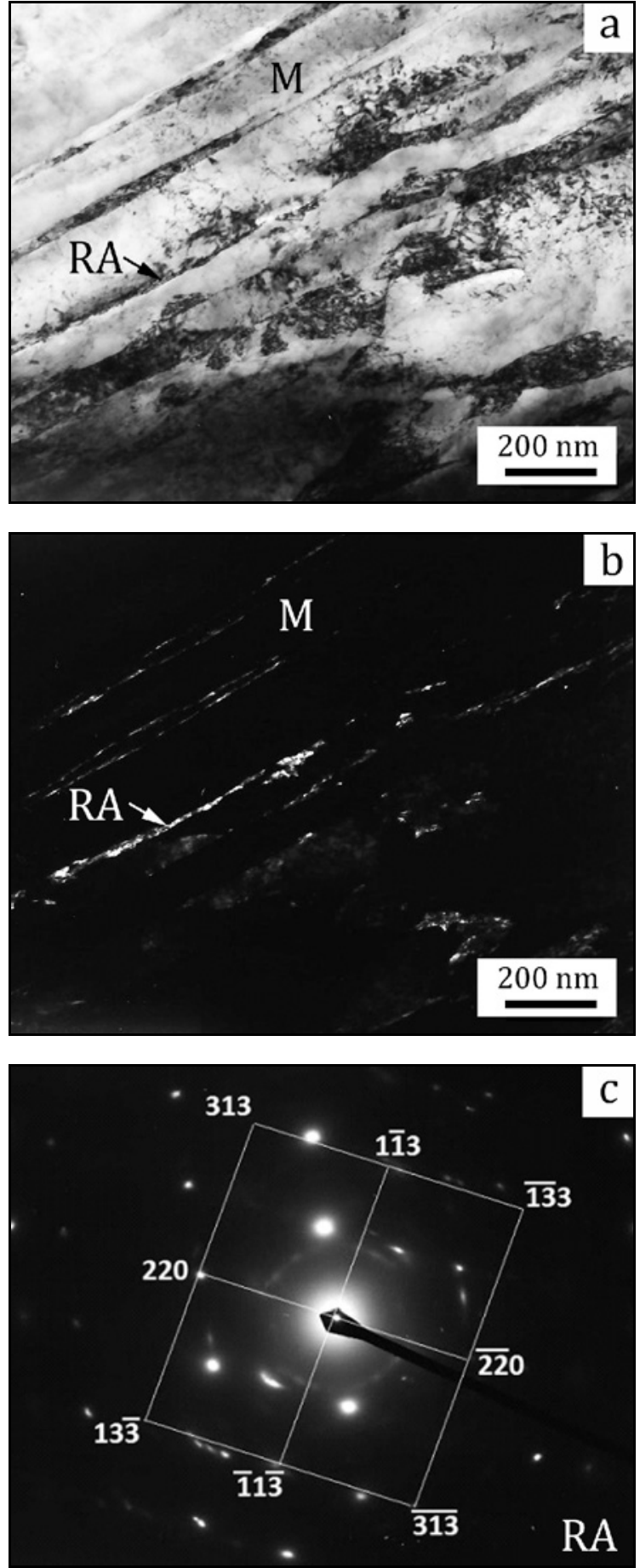

Fig. 5. Martensite with retained austenite in FZ of the weld: (a) bright field TEM image ( $\mathrm{M}$ - martensite, RA - retained austenite), (b) dark field TEM image with reflections of retained austenite, and (c) SAED pattern of retained austenite.

mation to austenite, is about $879^{\circ} \mathrm{C}$. Both temperatures decrease due to the larger cooling rates during the laser welding process [45]. Based on peak temperatures experienced during laser welding, the HAZ could be divided into supercritical HAZ (above $A_{3}$ critical
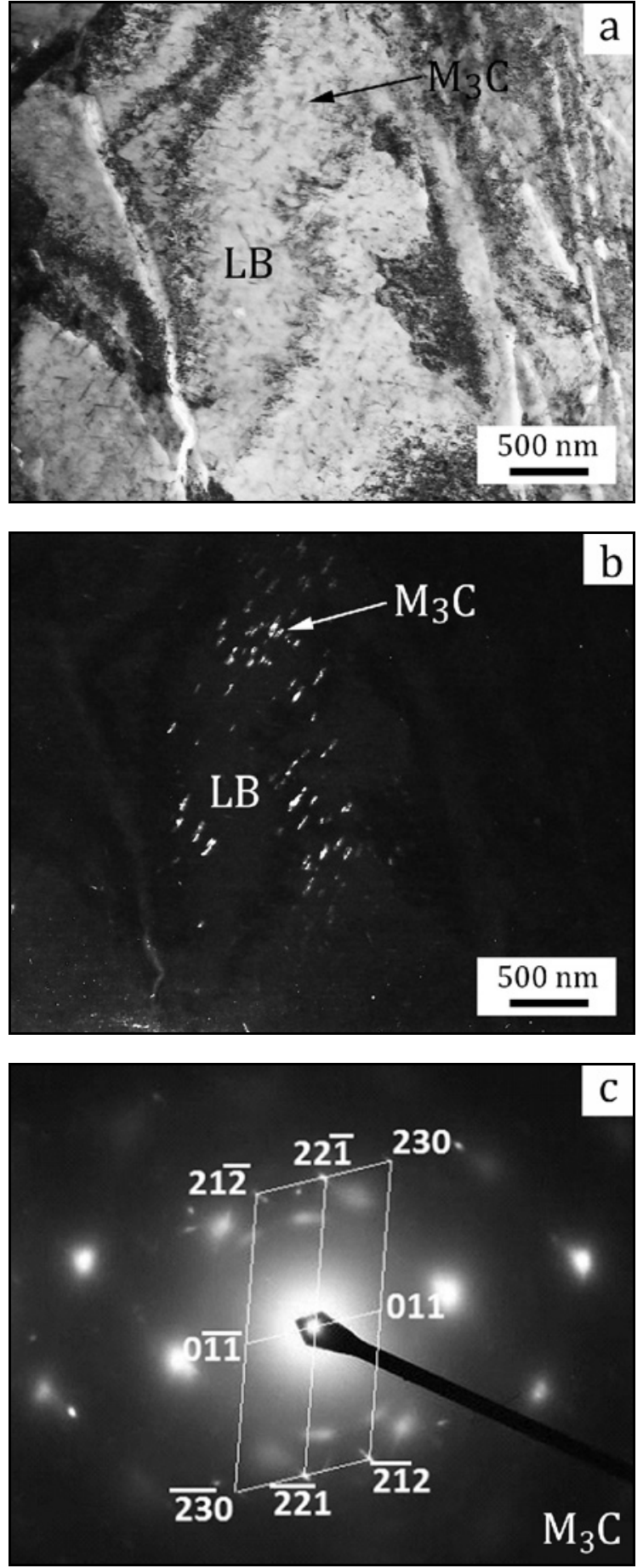

Fig. 6. Lower bainite in FZ of the weld: (a) bright field TEM image (LB - lower bainite, $\mathrm{M}_{3} \mathrm{C}$ - carbide precipitates), (b) dark field TEM image with reflections of $\mathrm{M}_{3} \mathrm{C}$ carbides, and (c) SAED pattern of $\mathrm{M}_{3} \mathrm{C}$ carbides.

temperature), intercritical HAZ (between $A_{1}$ and $A_{3}$ critical temperatures) and subcritical HAZ (below $A_{1}$ critical temperature). However, based on grain coarsening during laser welding, the HAZ could be divided into the coarse-grained and fine-grained region. The 

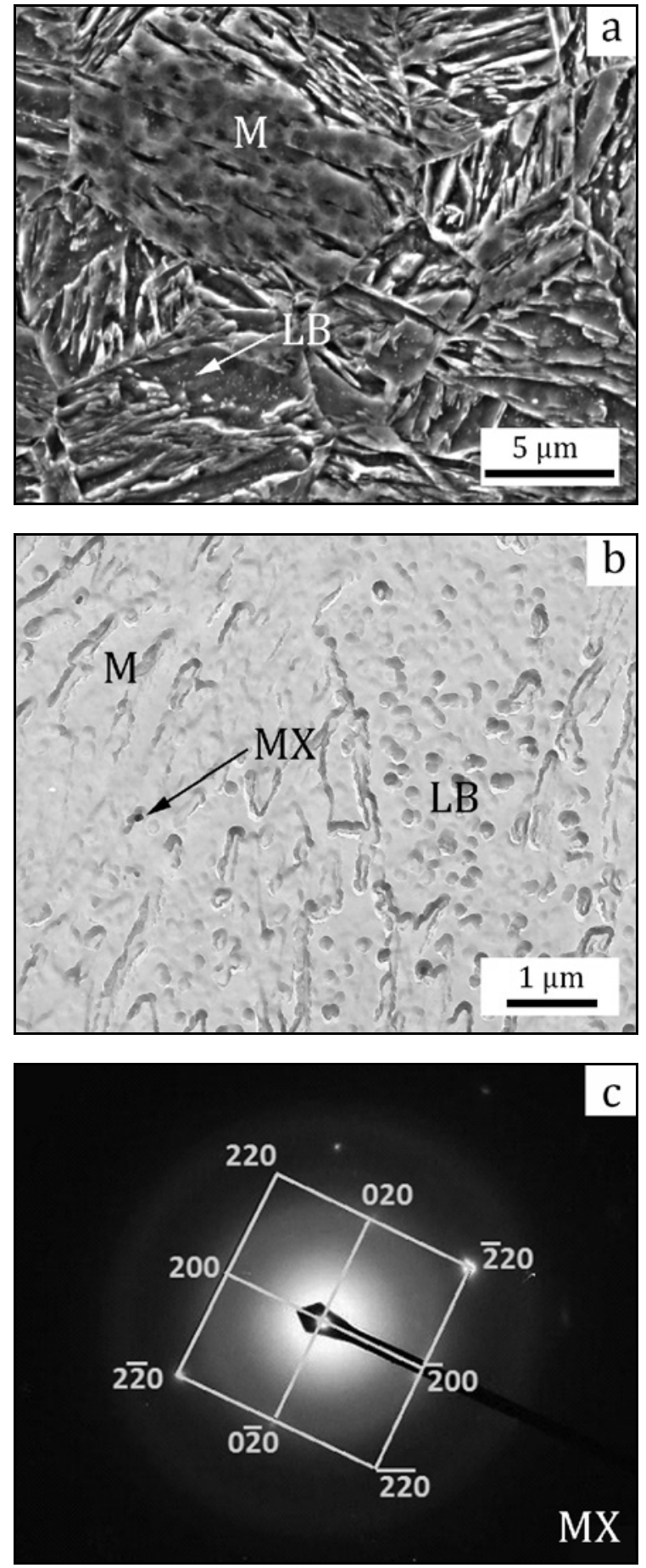

Fig. 7. The microstructures in the coarse-grained region of HAZ near DP980 steel: (a) SEM image, (b) TEM image (M - martensite, LB - lower bainite, MX - carbonitride precipitate), and (c) SAED pattern of MX carbonitride.

coarse-grained region is in the vicinity of fusion boundary in high tempered part of the supercritical HAZ. In this region, the original martensite and ferrite of the BM austenitise and then transform mostly to martensite under high cooling rate. Figure 7 represents SEM
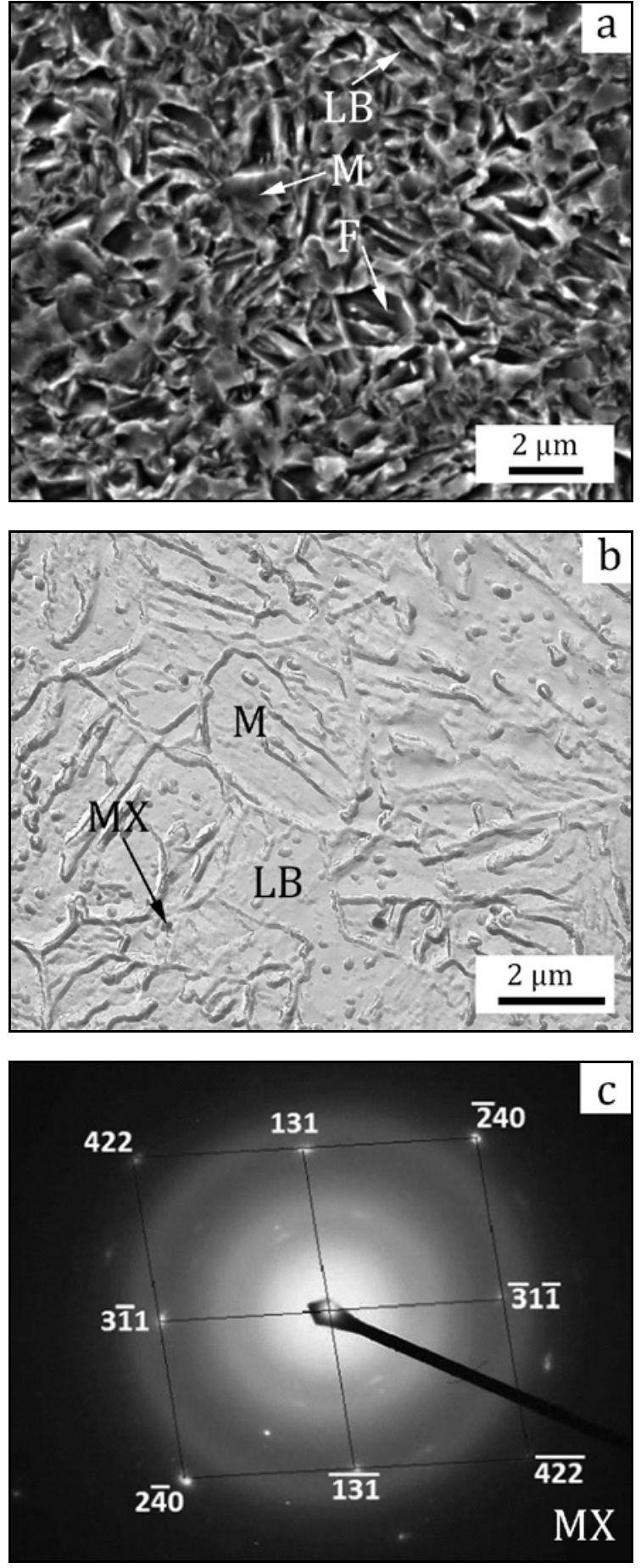

Fig. 8. The microstructures in the fine-grained region of HAZ near DP980 steel: (a) SEM image, (b) TEM image ( $\mathrm{F}$ - ferrite, $\mathrm{M}$ - martensite, LB - lower bainite, MX carbonitride precipitate), and (c) SAED pattern of MX carbonitride.

and TEM micrographs of the coarse-grained region of HAZ near DP980 steel with prior-austenite grain size in the interval from 35 to $45 \mu \mathrm{m}$. The dominant presence of lath martensite with a small portion of lower bainite can be seen in SEM micrograph in Fig. 7a. The 
identification of lath martensite, lower bainite, and MX carbonitride precipitates in the coarse-grained region of HAZ near DP980 steel was confirmed by carbon replica documented in Fig. 7b. MX carbonitride precipitates in martensite and extracted in the replica in Fig. 7b were identified by their SAED pattern in Fig. 7c.

With less heat input, fine-grained microstructure experienced within the intercritical range of $A_{\mathrm{c} 1}$ and $A_{\mathrm{c} 3}$ temperatures or with peak temperature close above $A_{\mathrm{c} 3}$ temperature. The fine-grained region of HAZ near DP980 steel is documented in Fig. 8. The sub-structure of this weld zone is built of martensite, lower bainite, ferrite and precipitating particles, as can be seen in SEM micrograph in Fig. 8a. The portion of lower bainite is small and microstructure in Fig. 8a is finer compared to the coarse-grained region in Fig. 7a. Similar microstructure depicted by carbon replica with extracted MX carbonitride precipitates but without the presence of ferrite is presented in Fig. 8b. The SAED pattern of the MX carbonitride precipitate is in Fig. 8c. The microstructure consisting of martensite and lower bainite but without ferrite (Fig. 8b) represents the fine-grained microstructure from the supercritical zone close above $A_{3}$ critical temperature, so with higher peak temperature reached during laser welding process compared to Fig. 8a.

The microstructures in HAZ near DP980 steel correspond with microstructures described in several works, where identical microconstituents were documented. In joint of DP600 with DP980 steel with a thickness of $1.2 \mathrm{~mm}$, in work [28], the microstructure in the supercritical HAZ near DP980 steel was built of equiaxed martensite, the intercritical HAZ region was built by ferrite and martensite. At fibre laser welding of DP980 with HSLA steel with thickness of $1.2 \mathrm{~mm}$ steel, fully martensitic microstructure in the supercritical HAZ near DP980 steel was observed, and the intercritical HAZ region was built by ferrite and martensite in works $[25,26]$, but the supercritical HAZ of DP980 steel was dominantly built of martensite, and the intercritical HAZ region was built by ferrite and martensite in works [31, 32]. In work [18], examination of HAZ near DP1000 steel with a thickness of $1.5 \mathrm{~mm}$ showed the presence of tempered martensite along with some possible bainite in conjunction with some pre-existing martensite in ferrite matrix [18].

\subsection{Microstructures in $H A Z$ near CP780 steel}

In consequence of the similar concentration of alloying elements in CP and DP steel, the microstructures in both HAZs are similar. In the coarse-grained region of the HAZ near CP780 steel in vicinity of the fusion boundary the peak temperature rises above $A_{\mathrm{c} 3}$, the microstructure passes complete reaustenitisation and rapid grain growth with prior-austenite grain
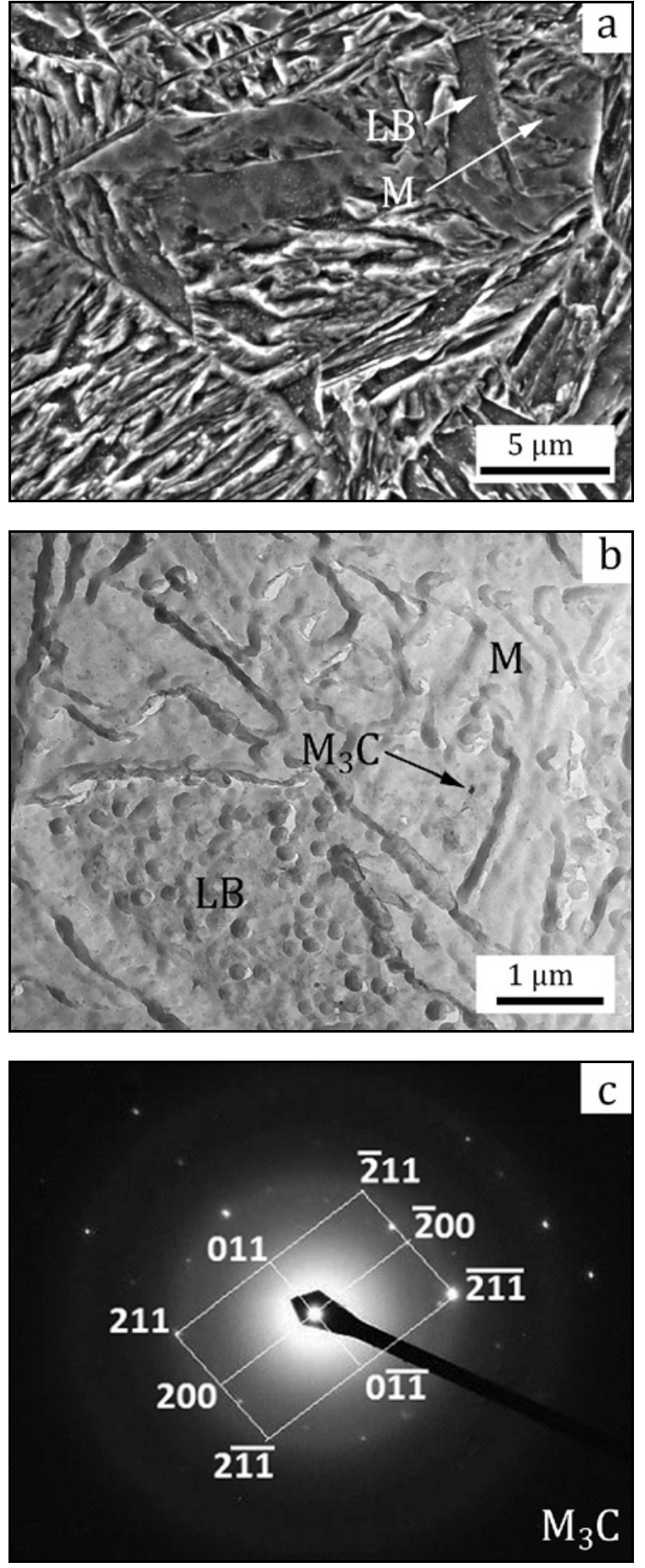

Fig. 9. The microstructures in the coarse-grained region of HAZ near CP780 steel: (a) SEM image, (b) TEM image ( $\mathrm{M}$ - martensite, $\mathrm{LB}$ - lower bainite, $\mathrm{M}_{3} \mathrm{C}$ - carbide phase), and (c) SAED pattern of $\mathrm{M}_{3} \mathrm{C}$ carbide.

size in the interval from 15 to $30 \mu \mathrm{m}$, which presents smaller coarsening of HAZ near CP780 steel compared to HAZ near DP980 steel. During rapid cooling following welding mainly martensite, lower bainite, and small $\mathrm{M}_{3} \mathrm{C}$ carbides formed. The morphological char- 

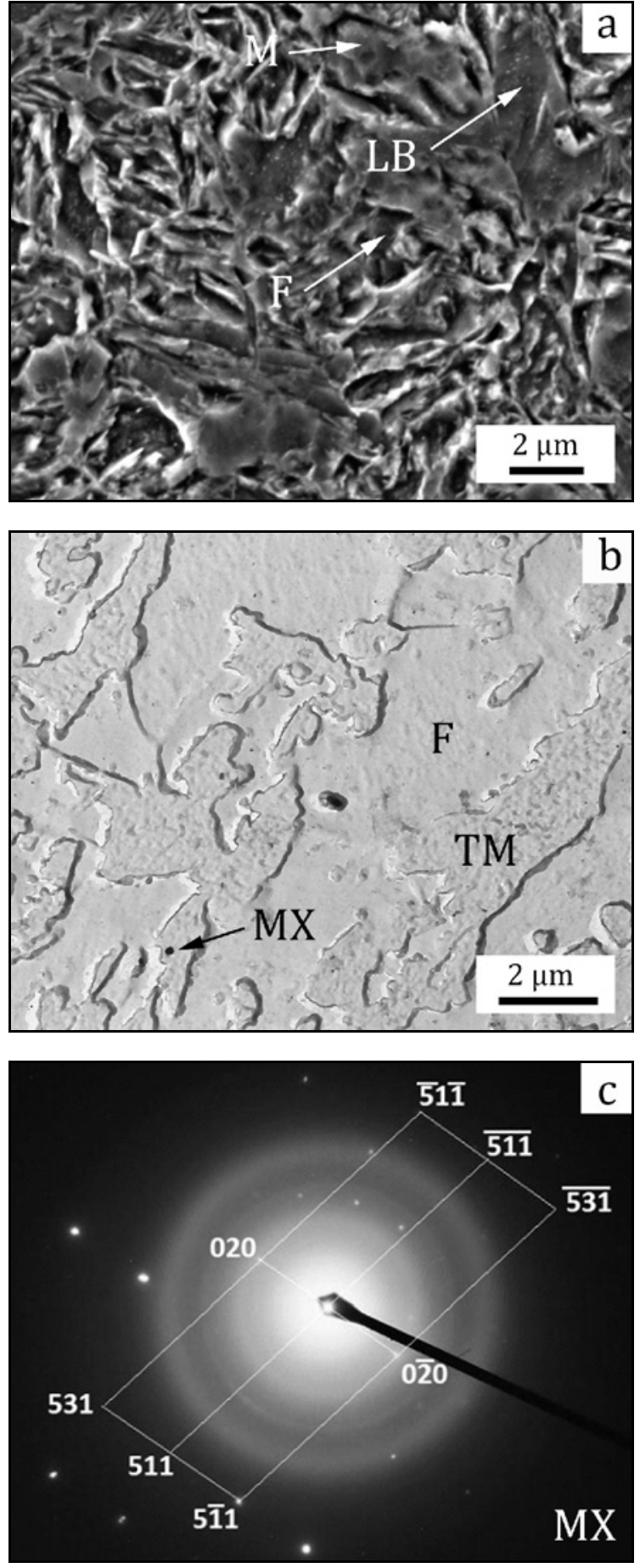

Fig. 10. The microstructures in the fine-grained region of HAZ near CP780 steel: (a) SEM image, (b) TEM image ( $\mathrm{F}$ - ferrite, LB - lower bainite, $\mathrm{M}$ - martensite, TM tempered martensite, $\mathrm{MX}$ - carbonitride precipitate), and (c) SAED pattern of MX carbonitride.

acteristics of lath martensite and lower bainite can be seen in SEM image in Fig. 9a and TEM carbon replica in Fig. 9b. The identification of the $\mathrm{M}_{3} \mathrm{C}$ carbide phases extracted in the carbon replica is documented in Fig. 9c. Besides $\mathrm{M}_{3} \mathrm{C}$ carbides very fine particles were observed in the matrix. These could not be identified by SAED, but they were probably MX carbonitrides.

The fine-grained region observed in the distant region of HAZ near CP780 is documented in Fig. 10. As the peak temperatures decrease towards $A_{\mathrm{c} 1}$ temperature with the distance from the fusion boundary, austenitisation is not complete, grains are finer, and less microstructure transformation occurs. During the heating period of welding, the transformation of CP780 steel BM structure (Fig. 3) starts with martensite, follows with lower bainite, and finishes with ferrite phase. However, the cooling rate is high during the cooling period of welding, and created austenite transforms again to martensite or lower bainite. At lower peak temperatures, below $A_{3}$ critical transformation temperature, a small portion of original ferrite can remain in structures, and tempering of martensite instead of its transformation can happen. The microstructure consisting of martensite, ferrite and lower bainite was observed in SEM micrograph in Fig. 10a, but ferrite, tempered martensite, and MX carbonitrides were observed in TEM micrograph in Fig. 10b. A higher portion of ferrite in TEM micrograph in Fig. $10 \mathrm{~b}$ is caused by lower peak temperature compared to SEM micrograph in Fig. 10a. Very fine MX carbonitrides extracted in carbon replica in Fig. 10b were identified by SAED pattern in Fig. 10c. Precipitation of MX carbonitrides in Fig. 10b presents tempering of martensite phase at this lower peak temperature.

The microstructures in Figs. 9 and 10 correspond with microstructures of laser welded joint of CP800 steel with a thickness of $2.5 \mathrm{~mm}$ described in work [43]. The HAZ in this work was composed of fine lath martensite. The microstructure of transition zone between BM and HAZ was characterised by a mixture of fine-grained ferrite, bainite, martensite and retained austenite. The content of ferrite grew along with a decreasing distance from the BM [43].

\subsection{Microhardness in sub-zones of the weld}

The microhardness profile measured across the mid-section of the welded joint is presented in Fig. 11. The microhardness values vary significantly because of the phase transformations occurred in the FZ and HAZs during the thermal welding cycle. The microhardness of DP980 steel BM is in the interval from 348 to $366 \mathrm{HV}_{0.1}$ and in a good agreement with finegrained dual phase ferrite and martensite microstructure of DP steel with an equal portion of both phases. The hardness of CP780 steel BM is in the interval from 252 to $278 \mathrm{HV}_{0.1}$, and this value represents the microstructure of CP steel consisting of ferrite, martensite and lower bainite.

The fast heating and cooling rates associated with 


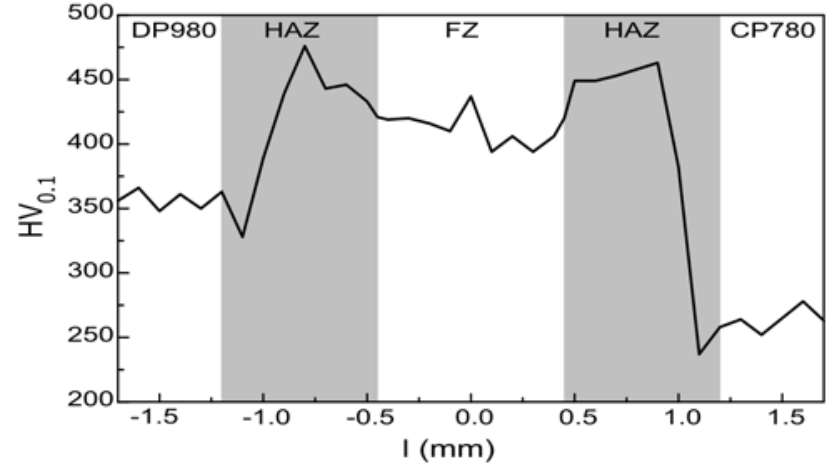

Fig. 11. Microhardness profile across the fibre laser welded joint.

fibre laser welding result in the generation of martensite and lower bainite with an approximately equal portion of these microconstituents in the FZ and dominant portion of martensite in both HAZs. Creation of hard microconstituents results in the maximum microhardness of $476 \mathrm{HV}_{0.1}$ in HAZ near DP980 steel and $463 \mathrm{HV}_{0.1}$ in HAZ near CP780 steel, respectively. The reduction of microhardness in HAZ near DP980 steel to the value of $328 \mathrm{HV}_{0.1}$ represents the $\mathrm{HAZ}$ softening region in the vicinity of DP980 steel BM in the subcritical zone. The lowest hardness value of 237 $\mathrm{HV}_{0.1}$ shows the HAZ softening region in the vicinity of CP980 steel BM. The higher decrease of microhardness values in the soft region of DP980 steel compared to CP780 steel can be explained because of higher volume portion of martensite in DP980 steel BM. More martensite was tempered in the subcritical HAZ near DP980 steel than in the subcritical HAZ near CP780 steel. The microhardness values in the interval from 384 to $437 \mathrm{HV}_{0.1}$ measured in the $\mathrm{FZ}$ respond to an equal portion of martensite and lower bainite in the FZ.

The measured microhardness values for DP980 steel BM representing the microstructure with an equal portion of martensite and ferrite can be confronted with [45] where average microhardness of $415 \mathrm{HV}_{0.1}$ for martensite and $225 \mathrm{HV}_{0.1}$ for ferrite phase was measured in DP980 steel with an equal portion of ferrite and martensite.

The microhardness values within the $\mathrm{FZ}$, on the one hand, vary with the fibre laser welding parameters, but on the other hand, they could be compared with several works $[1,11,18,28,43,46,47]$ that were devoted to laser welding of DP and CP steels. The microhardness within the FZ of joints of DP980 with DP600 steel with a thickness of $1.2 \mathrm{~mm}$ reached a maximum hardness of $456 \mathrm{HV}$ [1], $400 \mathrm{HV}$ [28], and from 370 to $420 \mathrm{HV}_{0.1}$ [47]. In joints of DP980 steel with a thickness of $1.2 \mathrm{~mm}$, the hardness in $\mathrm{FZ}$ reached $490 \mathrm{HV}$ [46], $470 \mathrm{HV}$ [11], and from 380 to $430 \mathrm{HV}$ [3]. The FZ of joints consisting of DP1000 with a thickness of $1.5 \mathrm{~mm}$ reached hardness up to $400 \mathrm{HV}_{0.2}$ [18]. In joints of CP800 steel with a thickness of $2.5 \mathrm{~mm}$ the hardness in FZ was from 365 to $393 \mathrm{HV}$ [43].

The microhardness values within the HAZ near DP980 can be compared with works $[1,3,9,18,25,26$, $28,31,32,43,46-49]$ in which DP980 steel was laser welded with different steel grades. At laser welding of DP980 with DP600 steel with a thickness of $1.2 \mathrm{~mm}$ the hardness in HAZ near DP980 steel was from 330 to $430 \mathrm{HV}$ [1], from $220 \mathrm{HV}_{0.2}$ to $340 \mathrm{HV}_{0.2}$ [28], from 320 to $460 \mathrm{HV}_{0.1}$ [47]. In joints of DP980 steel with a thickness of $1.2 \mathrm{~mm}$ hardness in HAZ was from 300 to $460 \mathrm{HV}_{0.2}$ [46], and from 240 to $460 \mathrm{HV}$ [3]. In joints of DP1000 steel with a thickness of $1.5 \mathrm{~mm}$ [18] the hardness in HAZ was from 320 to $340 \mathrm{HV}_{0.2}$ [18]. In joints of DP980 with HSLA steel with a thickness of $1.2 \mathrm{~mm}$ the hardness in HAZ near DP980 steel was from 280 to $420 \mathrm{HV}$ [25, 26], from 260 to $380 \mathrm{HV}_{0.2}$ $[31,32]$, from 314 to $464 \mathrm{HV}_{0.1}$ [48], and from 360 to $505 \mathrm{HV}_{0.1}[49]$.

The microhardness values within the HAZ near CP780 could be compared with work [43], where in joint of CP800 steel with a thickness of $2.5 \mathrm{~mm}$ the hardness from $270 \mathrm{HV}$ to 393 was measured in HAZ near CP800 steel [43].

The reduction of hardness in HAZ near DP980 steel in the softening region is smaller compared to works $[1,3,9,18,28,46]$. Authors of these works measured the minimum hardness of $220 \mathrm{HV}$ [28], $224 \mathrm{HV}$ [18], $240 \mathrm{HV}$ [3], $260 \mathrm{HV}$ [9], $280 \mathrm{HV}[25,26], 282 \mathrm{HV}$ [1], and $300 \mathrm{HV}$ [46]. In joints of DP1000 steel with a thickness of $1.5 \mathrm{~mm}$ the hardness in the HAZ softening region was from 224 to $293 \mathrm{HV}_{0.2}$ in work [18]. The soft region in HAZ near CP780 steel can be compared with the value of $270 \mathrm{HV}$ measured at welding of joint of CP800 steel with a thickness of $2.5 \mathrm{~mm}$ [43].

\subsection{Tensile tests of laser welded joint}

The tensile tests showed joint strengths from 823 to $826 \mathrm{MPa}$ and joint elongations from 8.6 to $9.3 \%$. The strength of fibre laser welded joints reached the minimal tensile strength of weaker CP780 steel $\mathrm{BM}$ (min. $780 \mathrm{MPa}$ in Table 2) with a fracture of all joints in CP780 steel BM. Slightly lower joint elongations than minimum value of both DP980 and 780C steel (min. $10 \%$ in Table 2) confirm strengthening of the weld by laser welding process and minimal yielding of weld region. The creation of harder microconstituents in weld region confirmed by microhardness values in Fig. 11 is accompanied with the strength increasing in the FZ and main parts of both HAZs.

\section{Conclusions}

The fibre laser welding of dual phase DP980 steel with complex phase CP780 steel was studied with a 
concentration on microstructure in the sub-zones of the weld using SEM and TEM analysis. The joints welded using fibre laser process were characterised by hourglass shape typical for penetration keyhole welding and with the slight concavity of the face and root sagging.

An approximately equal portion of lath martensite and lower bainite was observed in the large columnar grain structure of the FZ. Retained austenite was observed between the martensitic laths, and $\mathrm{M}_{3} \mathrm{C}$ carbide precipitates were identified in lower bainite. The microstructures of both coarse-grained regions of HAZ near DP980 and HAZ near 780C steel consisted of major portion of martensite and a minor portion of lower bainite. Predominantly $\mathrm{M}_{3} \mathrm{C}$ carbide precipitates were identified in lower bainite, and mainly MX carbonitride precipitates were confirmed in the martensite phase. The microstructure consisting of martensite, lower bainite and MX carbonitrides was observed in the fine-grained region of HAZ near DP980 steel heated at higher peak temperature. Martensite, lower bainite, and ferrite were identified in the same fine-grained region of HAZ near DP980 steel heated to lower peak temperature. In the fine-grained region of HAZ near CP780 steel microstructure consisting of martensite, ferrite, and lower bainite was observed at higher peak temperature and microstructure consisting of ferrite, tempered martensite, and MX carbonitrides was observed at lower peak temperature. These hard microconstituents were the consequence of rapid cooling in the FZ and HAZs of the welded joint.

Microhardness profile across the welded joint was characterised by increased microhardness values in FZ, both HAZs, and with HAZ softening in HAZ near DP980 and CP780 steel. As the microstructure in the sub-zones of the weld was mainly built of martensite and lower bainite with a various portion of these phases, small differences in maximum hardness values within FZ and both HAZs were measured. The maximum microhardness across the welded joint was measured within the coarse-grained region of $\mathrm{HAZ}$ near DP980 steel with the value of $476 \mathrm{HV}_{0.1}$. The maximum hardness in the HAZ near CP780 steel reached $463 \mathrm{HV}_{0.1}$. The softening region in $\mathrm{HAZ}$ near DP980 steel was characterised with a minimum hardness of $328 \mathrm{HV}_{0.1}$ and in HAZ near CP780 steel with a value of $237 \mathrm{HV}_{0.1}$. The hardness in the $\mathrm{FZ}$ was in the interval from 384 to $437 \mathrm{HV}_{0.1}$. The tensile strengths of the fibre laser welded joints were from 823 to $826 \mathrm{MPa}$, and these values reached the tensile strength of weaker CP780 steel with all joints broken in CP780 steel BM. The welded joint elongations from 8.6 to $9.3 \%$ were slightly lower compared to the minimum value of both DP980 and 780C steel and confirmed strengthening of the weld by laser welding process.

\section{Acknowledgement}

This work was supported by the Slovak Research and Development Agency under the contract No. APVV-028112 .

\section{References}

[1] Jia, Q., Guo, W., Li, W., Zhu, Y., Peng, P., Zou, G.: Journal of Materials Processing Technology, 236, 2016, p. 73. doi:10.1016/i.jmatprotec.2016.05.011

[2] Lun, N., Saha, D. C., Macwan, A., Pan, H., Wang, L., Goodwin, F., Zhou, Y.: Materials and Design, 131, 2017, p. 450. doi:10.1016/j.matdes.2017.06.037

[3] Bandyopadhyay, K., Panda, S. K., Saha, D. C., Baltazar-Hernandez, V. H., Zhou, Y. N.: Materials Science and Engineering A, 652, 2016, p. 250. doi:10.1016/i.msea.2015.11.091

[4] Ni, J., Li, Z., Huang, J., Wu, Y.: Materials and Design, 31, 2010, p. 4876. doi:10.1016/j.matdes.2010.15.034

[5] Forouzan, F., Vuorinen, E., Mücklich, F.: Materials Science \& Engineering A, 698, 2017, p. 174. doi:10.1016/j.msea.2017.05.053

[6] Guo, W., Li, L., Dong, S., Crowther, D., Thompson, A.: Optics and Laser in Engineering, 91, 2017, p. 1. doi:10.1016/j.optlaseng.2016.11.011

[7] Merklein, M., Johannes, M., Lechner, M., Kuppert, A.: Journal of Materials Processing Technology, 214, 2014, p. 151. doi:10.1016/i.jmatprotec.2013.08.015

[8] Hong, K.-M., Shin, Y. C.: Journal of Materials Processing Technology, 245, 2017, p. 46. doi:10.1016/i. jmatprotec.2017.02.008

[9] Sharma, R. S., Molian, P.: Journal of Materials Processing Technology, 211, 2011, p. 1888. doi:10.1016/j. jmatprotec.2011.06.009

[10] Xu, F., Sun, G., Li, G., Li, Q.: Journal of Materials Processing Technology, 214, 2014, p. 925. doi:10.1016/j. jmatprotec.2013.11.0

[11] Cui, Q. L., Parkes, D., Westerbaan, D., Nayak, S. S., Zhou, Y., Liud, D., Goodwin, F., Bhole, S., Chen, D. L.: Materials and Design, 90, 2016, p. 516. doi:10.1016/j.matdes.2015.10.098

[12] Fereiduni, E., Ghasemi Banadkouki, S. S.: Journal of Alloys and Compounds, 557, 2013, p. 351. doi:10.1016/j.jallcom.2013.05.209

[13] Rossini, M., Russo Spena, P., Cortese, L., Matteis, P., Firrao, D.: Materials Science \& Engineering A, 628, 2015, p. 288. doi:10.1016/j. msea.2015.01.037

[14] Schemmann, L., Zaefferer, S., Raabe, D., Friedel, F., Mattissen, D.: Acta Materialia, 95, 2015, p. 386. doi:10.1016/j.actamat.2015.05.005

[15] Banadkouki, S. S. G., Fereiduni, E.: Materials Science \& Engineering A, 619, 2014, p. 129. doi:10.1016/j.msea.2014.09.041

[16] Shi, L., Yan, Z., Liu, Y., Zhang, C., Qiao, Z., Ning, B., Li, H.: Materials Science \& Engineering A, 590, 2014, p. 7. doi:10.1016/j.msea.2013.10.006

[17] Sinha, A. K., Kim, D. Y., Ceglarek, D.: Optics and Laser in Engineering, 51, 2013, p. 1143. doi:10.1016/j.optlaseng.2013.04.012

[18] Wang, J., Yang, L., Sun, M., Liu, T., Li, H.: Materials and Design, 90, 2016, p. 642. doi:10.1016/j.matdes.2015.11.006 
[19] Sowards, J. W., Pfeif, E. A., Connolly, M. J., McColskey, J. D., Miller, S. L., Simonds, B. J., Fekete, J. R.: Materials and Design, 121, 2017, p. 393. doi:10.1016/i.matdes.2017.02.065

[20] Rong, Y., Xu, J., Haiyin, C., Zheng, H., Huang, Y., Zhang, G.: Journal of Manufacturing Processes, 26, 2007, p. 399. doi:10.1016/j.mapro.2017.03.007

[21] Puchý, V., Falat, L., Kováč, F., Petryshynets, I., Džunda, R., Šebek, M.: Acta Physica Polonica A, 131, 2017, p. 1445. doi:10.12693/APhysPolA.131.1445

[22] Gong, H., Wang, S., Knysh, P., Korkolis, Y. P.: Materials and Design, 90, 2016, p. 1115. doi:10.1016/j.matdes.2015.11.057

[23] Mei, L., Chen, G., Jin, X., Zhang, Y., Wu, Q.: Optics \& Laser Technology, 47, 2009, p. 1117. doi:10.1016/i.optlaseng.2009.06.016

[24] Viňáš, J., Ábel, M.: Materials Science Forum, 818, 2015 , p. 239. doi:10.4028/www.scientific.net/MSF.818.239

[25] Xu, W., Westerbaan, D., Nayak, S. S., Chen, D. L., Goodwin, F., Zhou, Y.: Materials and Design, 43, 2013, p. 373. doi:10.1016/j.matdes.2012.07.017

[26] Xu, W., Westerbaan, D., Nayak, S. S., Chen, D. L., Goodwin, F., Biro, E., Zhou, Y.: Materials Science and Engineering A, 533, 2012, p. 51. doi:10.1016/j.msea.2012.05.091

[27] Farabi, N., Chen, D. L., Li, J., Zhou, Y., Dong, S. J.: Materials Science and Engineering A, 527, 2010, p. 1215. doi:10.1016/j.msea.2009.09.051

[28] Farabi, N., Chen, D. L., Zhou, Y.: Journal of Alloys and Compounds, 509, 2011, p. 982. doi:10.1016/j.jallcom.2010.08.158

[29] Meško, J., Zrak, A., Mulczyk, K., Tofil, S.: Manufacturing Technology, 14, 2014, p. 355.

[30] Ma, J., Kong, F., Liu, W., Carlson, B., Kovacevic, R.: Journal of Materials Processing Technology, 214, 2014, p. 1696. doi:10.1016/j.jmatprotec.2014.03.018

[31] Parkes, D., Westerbaan, D., Nayak, S. S., Zhou, Y., Goodwin, F., Bhole, S., Chen, D. L.: Materials and Design, 56, 2014, p. 193. doi:10.1016/j.matdes.2013.10.087

[32] Parkes, D., Xu, W., Westerbaan, D., Nayak, S. S., Zhou, Y., Goodwin, F., Bhole, S., Chen, D. L.: Materials and Design, 51, 2013, p. 665 . doi:10.1016/j.matdes.2013.04.076

[33] Dong, D., Liu, Y., Yang, Y., Li, J., Ma, M., Jing, T.: Materials Science \& Engineering A, 594, 2014, p. 17. doi:10.1016/j.msea.2013.11.047
[34] Hazratinezhad, H., Mostafa Arab, N. B., Sufizadeh, A. R., Torkomany, M. J.: Materials and Design, 33, 2012, p. 83. doi:10.1016/j.matdes.2011.06.070

[35] Lee, J. H., Park, S. H., Kwon, H. S., Kim, G. S., Lee, C. S.: Materials and Design, 64, 2014, p. 559. doi:10.1016/j.matdes.2014.07.065

[36] Li, J., Nayak, S. S., Biro, E., Panda, S. K., Goodwin, F., Zhou, Y.: Materials and Design, 52, 2013, p. 757. doi:10.1016/i.matdes.2013.06.021

[37] Grajcar, A., Morawiec, M., Różański, M., Stano, S.: Optics \& Laser Technology, 92, 2017, p. 52. doi:10.1016/j.optlastec.2017.01.011

[38] Mujica, L., Weber, S., Pinto, H., Thomy, C., Vollertsen, F.: Materials Science \& Engineering A, 527, 2010, p. 2071. doi:10.1016/j.msea.2009.11.050

[39] Evin, E., Tomáš, M.: Metals, 7, 2017, p. 239. doi:10.3390/met7070239

[40] Reisgen, U., Schleser, M., Mokrov, O., Ahmed, E.: Optics \& Laser Technology, 44, 2012, p. 255. doi:10.1016/j.optlastec.2011.06.028

[41] Reisgen, U., Schleser, M., Mokrov, O., Ahmed, E.: Optics \& Laser Technology, 44, 2012, p. 92. doi:10.1016/i.optlastec.2011.05.025

[42] Sharma, R. S., Molian, P.: Materials and Design, 30, 2009, p. 4146. doi:10.1016/j.matdes.2009.04.033

[43] Morawiec, M., Różański, M., Grajcar, A., Stano, S.: Archives of Civil and Mechanical Engineering, 17, 2017, p. 145. doi:10.1016/i.acme.2016.09.007

[44] Guo, W., Crowther, D., Francis, J. A., Thompson, A., Liu, Z., Li, L.: Materials and Design, 85, 2015, p. 534. doi:10.1016/j.matdes.2015.07.037

[45] Krajewski, S., Nowacki, J.: Archives of Civil and Mechanical Engineering, 14, 2014, p. 278. doi:10.1016/j.acme.2013.10.002

[46] Saha, D. C., Westerbaan, D., Nayak, S. S., Biro, E., Gerlich, A. P., Zhou, Y.: Materials Science and Engineering A, 607, 2014, p. 445. doi:10.1016/j.msea.2014.14.034

[47] Svec, P., Schrek, A., Hrnčiar, V., Csicsó, T.: Acta Metallurgica Slovaca, 21, 2015, p. 311. doi:10.12776/ams.v2Ii4.262

[48] Svec, P., Schrek, A.: Strength of Materials, 49, 2017, p. 531. doi:10.1007/s11223-017-9896-y

[49] Švec, P., Schrek, A.: MM Science Journal, 2016, p. 1304. doi:10.17973/MMSJ.2016_11_2016109 